\title{
Caracterização dos frutos de maracujá amarelo irrigados com água salina ${ }^{1}$
}

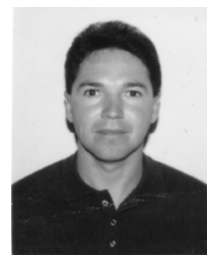

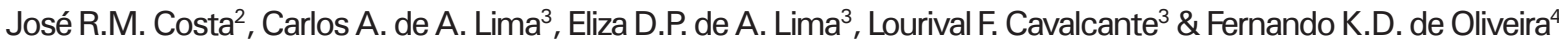 \\ 1 Parte da Dissertação de Mestrado do primeiro autor \\ 2 ETAC, CEP 58175-000, Cuité, PB. Fone: (83) 372-2730. E-mail: ronagro@zipmail.com.br (Foto) \\ ${ }^{3}$ UFPB/CCA, CEP 58397-000, Areia, PB. Fone: (83) 362-2300. E-mail: lofeca@cca.ufpb.br \\ 4 Prodesiano/Banco do Nordeste
}

Protocolo $116-11 / 09 / 2000$

\begin{abstract}
Resumo: Com o objetivo de se caracterizar frutos de maracujazeiro amarelo (Passiflora edulis $\mathrm{f}$. flavicarpa Deg) irrigados com água salina, desenvolveu-se um experimento em Santa Cruz, RN, zona semi-árida do Brasil, cujos tratamentos foram distribuídos em blocos casualizados, com quatro repetições, em esquema fatorial $5 \times 2$, correspondente ao sem revestimento $\left(R_{0}\right)$ e com revestimento das faces $\left(R_{1} ; R_{2} ; R_{3} ; R_{4}\right.$; respectivamente uma, duas, três e quatro faces) irrigadas diariamente com volumes de 5 e $10 \mathrm{~L}$ de água. A salinidade da água, superior a $3,0 \mathrm{dS} \mathrm{m}^{-1}$, não interferiu sobre a qualidade externa nem interna dos frutos. O aumento do volume de água resultou em maior massa média dos frutos. A proteção das covas não influenciou o comprimento, diâmetro e número de sementes por fruto nem a espessura da casca, rendimento em polpa, sólidos solúveis totais, acidez total titulável e teores de vitamina $\mathrm{C}$ total.
\end{abstract}

Palavras-chave: salinidade, sólidos solúveis, Passiflora edulis

\section{Characterization of fruits of yellow passion fruit irrigated with saline water}

\begin{abstract}
With the purpose of characterizing fruits of yellow passion fruit (Passiflora edulis $\mathrm{f}$. flavicarpa Deg) in plants irrigated with saline water, an experiment was conducted at Santa Cruz, $\mathrm{RN}$, in the semi-arid zone of Brazil. The treatments were distribuited in randomized blocks, with four repetitions, using factorial design $5 \times 2$ corresponding the planting pits without coating $\left(R_{0}\right)$ and with side coatings $\left(R_{1} ; R_{2} ; R_{3} ; R_{4}\right.$; respectively one, two, three and four lateral sides $)$, irrigated daily with volumes of 5 and $10 \mathrm{~L}$ of water. The water salinity higher then $3.0 \mathrm{dS} \mathrm{m}^{-1}$ did not show effect on the external and internal quality of the fruits. The increase of the volume of water resulted in larger mean weight of the fruits. The protection of the planting pits did not influence the length, diameter or number of seeds for fruit and neither the peel thickness, pulp percentage, total soluble solids, total titratable acidity or total vitamin $\mathrm{C}$ contents.
\end{abstract}

Key words: salinity, total soluble solids, Passiflora edulis

\section{INTRODUÇÃO}

O maracujá amarelo (Passiflora edulis f. flavicarpa Deg) tem o Brasil como maior produtor mundial e as regiões do Norte e Nordeste destacam-se com a maior parcela de produção. Particularmente no Rio Grande do Norte, diversos municípios produzem essa frutífera em escala comercial e sua potencialidade econômica está associada ao rápido retorno de capital, à preferência pelos mercados interno e externo, devido ao aroma agradável, teores de açúcares, vitaminas A e C, além da sua composição mineral, que definem a qualidade do suco (Falconner et al.,1998).

A qualidade tecnológica de frutos de maracujá amarelo exigida pelos mercados "in natura" e para fins industriais, deve apresentar acidez total titulável entre 3,2 e 4,5\%, conteúdo de sólidos solúveis - ${ }^{\circ}$ brix, oscilando de 15 a $16 \%$, rendimento em

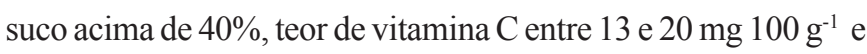
peso médio do fruto acima de $120 \mathrm{~g}$ (Ruggiero et al.,1996; São José et al.,1999).

Além dos fatores que influem sobre as características físico-químicas do maracujá, como estádio de maturação, idade das plantas, condições edafo-climáticas, estado nutricional, polinização e fertilização do solo (Ritzinger et al.,1989) o manejo da água utilizada na irrigação assume destacada importância para o incremento da produção e qualidade dos frutos (Carvalho et al., 1999).

A produção e a qualidade de frutos de maracujá podem variar entre regiões e localidades, conforme o manejo adotado. Queirós et al. (1998) irrigaram plantas de maracujá amarelo com água de boa qualidade e obtiveram os seguintes resultados: sólidos solúveis totais - ${ }^{\circ}$ brix de 11 a $16 \%$, acidez total titulável entre 2,8 a 3,6\% e rendimento em polpa variando de 36 a $41 \%$. Teixeira et 
al. (1990) produziram maracujazeiro amarelo sob fertirrigação e a caracterização físico-química dos frutos apresentou peso médio de até $146 \mathrm{~g}$, sólidos solúveis totais - 'orix 9,6 a 16,8\% e acidez titulável de 3,0 a 5,8\%.

Quanto aos efeitos da salinidade da água de irrigação sobre a produção e qualidade dos frutos do maracujazeiro amarelo, as informações científicas são ainda limitadas. A redução das perdas hídricas com auxílio da proteção lateral das covas deve contribuir para a diminuição dos efeitos depressivos dos sais às plantas, conforme concluiu Andrade (1998) após cultivar maracujá amarelo irrigado com água de até $2,5 \mathrm{dS} \mathrm{m}^{-1}$, em covas revestidas lateralmente com filme de polietileno, verificou, também que o teor salino da água de irrigação não interferiu significativamente sobre o peso médio do fruto, comprimento, diâmetro, espessura da casca, número e peso de sementes por fruto, rendimento em polpa, teor de sólidos solúveis totais obrix, e acidez total titulável.

O presente trabalho teve como objetivo avaliar o efeito de volumes de água salina e revestimento de covas com filme de polietileno sobre algumas características físicas e químicas de frutos de maracujá amarelo.

\section{MATERIAL E MÉTODOS}

O trabalho foi realizado no período de março /1999 a fevereiro/ 2000, numa área de Luvissolo, bem drenado, profundidade maior que $1 \mathrm{~m}$, da Fazenda Jacaracica, município de Santa Cruz, área semi-árida do Rio Grande do Norte. O clima é do tipo semi-árido (quente e seco), com pluviosiodade inferior a $600 \mathrm{~mm}$ anuais e temperatura média de 24 a $30^{\circ} \mathrm{C}$. A precipitação pluviométrica do local durante a realização do ensaio foi: março $(139 \mathrm{~mm})$, abril (37 mm), maio (155 mm), junho (21 mm), julho (12 mm), agosto (13 mm), setembro $(0 \mathrm{~mm})$, outubro $(6 \mathrm{~mm})$, novembro $(0 \mathrm{~mm})$, dezembro $(19 \mathrm{~mm})$, janeiro $(21 \mathrm{~mm})$ e fevereiro $(327 \mathrm{~mm})$ respectivamente.

Os tratamentos foram distribuídos em blocos casualizados com quatro repetições e três plantas por parcela, em esquema fatorial $5 \times 2$, correspondente à ausência do revestimento $\left(\mathrm{R}_{0}\right) \mathrm{e}$ presença de revestimentos das faces laterais das covas com filme de polietileno $\left(\mathrm{R}_{1}, \mathrm{R}_{2}, \mathrm{R}_{3}, \mathrm{R}_{4}\right.$, respectivamente uma, duas, três e quatro faces) irrigadas diariamente com 5 e $10 \mathrm{~L}$, no período de estiagem, pelo método de gotejamento, com água de condutividade elétrica $3,2 \mathrm{dS} \mathrm{m}^{-1}$, proveniente de um poço tubular; o plantio se deu em covas de 50 × 50 × $40 \mathrm{~cm}$, na distância de $2 \mathrm{~m}$ entre linhas e $4 \mathrm{~m}$ nas linhas. $\mathrm{O}$ sistema de sustentação foi espaldeira com um fio de arame liso $\mathrm{n}^{\circ} 12$, instalado a $2,0 \mathrm{~m}$ de altura.

A colheita compreendeu o período de outubro de 1999 a janeiro de 2000; a partir daí, os frutos foram caracterizados fisicamente pelo peso médio, comprimento, diâmetro, espessura da casca, número e peso de sementes e rendimento em polpa. A caracterização química referiu-se aos sólidos solúveis totais obrix, determinados por refratometria; acidez total titulável-ATT (Instituto Adolf Lutz,1985); relação sólidos solúveis totais/ acidez total titulável e vitamina $\mathrm{C}$ total (ácido L-ascórbico-AA e ácido disidroascórbico-DHAA) determinada pelo método titulométrico, com 2,6-diclorofenolindofenol (DFI) da AOAC (Cunniff,1997) modificando-se a solução de extração com o ácido oxálico a $5 \%$ e desenvolvendo a reação de redução do DHAA com DL-homocisteína, nas condições estabelecidas por Aldrigue (1998).
Os dados foram submetidos à análise de variância, pelo teste "F", comparação dos contrastes pelo teste de Tukey e regressão polinomial.

\section{RESULTADOS E DISCUSSÃO}

O peso médio dos frutos (Tabela 1) não foi influenciado pelo revestimento das covas com filme plástico mas, por outro lado, registrou-se superioridade estatística do volume de água sobre esta variável. Os valores variaram de 112,31 a 123,85 g, com superioridade relativa aos tratamentos onde as covas tinham as quatro faces revestidas. Os resultados, apesar de inferiores a $146 \mathrm{~g}$ alcançados por Teixeira et al. (1990) foram considerados satisfatórios para o mercado (Ruggiero et al., 1996); no entanto, conforme São José et al. (1999) produções de frutos com peso médio inferior a $120 \mathrm{~g}$ podem não ser economicamente viáveis. Os dados relativos às plantas irrigadas com $5 \mathrm{~L} \mathrm{~d}^{-1}$, ajustaram-se com maior significância ao modelo cúbico e dos tratamentos com $10 \mathrm{~L} \mathrm{~d}^{-1}$, ao modelo quadrático (Figura 1).

Tabela 1. Efeito das fontes de variação sobre o peso, comprimento, diâmetro e espessura da casca de frutos de maracujazeiro amarelo (Passiflora edulis f. flavicarpa Deg.) ${ }^{*}$

\begin{tabular}{|c|c|c|c|c|}
\hline $\begin{array}{l}\text { Fontes de } \\
\text { Variação }\end{array}$ & $\begin{array}{l}\text { Peso } \\
\text { Médio }\end{array}$ & Comprimento & Diâmetro & $\begin{array}{l}\text { Espessura } \\
\text { da Casca }\end{array}$ \\
\hline R. L. C. & g & & $\mathrm{mm}$ & \\
\hline $\mathrm{R}_{0}=0$ face & $115,35 \mathrm{a}$ & $64,15 \mathrm{~b}$ & $61,06 \mathrm{~b}$ & $7,95 \mathrm{a}$ \\
\hline $\mathrm{R}_{1}=1$ face & $118,75 \mathrm{a}$ & $72,31 \mathrm{a}$ & $67,67 \mathrm{a}$ & 8,16 a \\
\hline $\mathrm{R}_{2}=2$ faces & $116,52 \mathrm{a}$ & $68,82 \mathrm{ab}$ & $65,30 \mathrm{ab}$ & $7,93 \mathrm{a}$ \\
\hline $\mathrm{R}_{3}=3$ faces & $112,31 \mathrm{a}$ & $68,86 \mathrm{ab}$ & $68,55 \mathrm{a}$ & 8,47 a \\
\hline $\mathrm{R}_{4}=4$ faces & $123,85 \mathrm{a}$ & $70,63 \mathrm{ab}$ & $66,52 \mathrm{a}$ & $7,76 \mathrm{a}$ \\
\hline Média & 117,35 & 68,95 & 65,82 & 8,05 \\
\hline DMS & 12,22 & 7,03 & 5,95 & 1,36 \\
\hline V. A. & $\mathrm{g}$ & $\mathrm{mm}$ & $\mathrm{mm}$ & $\mathrm{mm}$ \\
\hline $\mathrm{V}_{1}=5 \mathrm{~L}$ & $114,16 \mathrm{~b}$ & $67,97 \mathrm{a}$ & $65,14 \mathrm{a}$ & $8,31 \mathrm{a}$ \\
\hline $\mathrm{V}_{2}=10 \mathrm{~L}$ & $120,55 \mathrm{a}$ & $70,94 \mathrm{a}$ & $66,50 \mathrm{a}$ & $7,90 \mathrm{a}$ \\
\hline Média & 117,35 & 68,95 & 65,82 & 8,05 \\
\hline DMS & 5,43 & 3,12 & 2,64 & 0,60 \\
\hline $\mathrm{CV}(\%)$ & 7,13 & 6,98 & 6,18 & 11,58 \\
\hline
\end{tabular}

"Médias seguidas de letras distintas nas colunas diferem significativamente pelo teste de Tukey, a 0,05 de probabilidade

R. L. C. = Revestimento lateral de covas, V. A. = Volumes de água

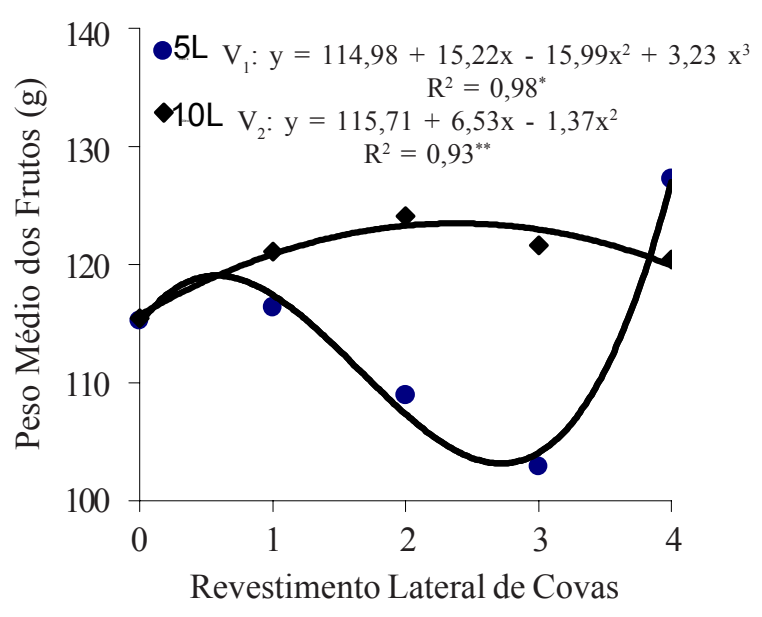

Figura 1. Valores do peso médio dos frutos em função do revestimento lateral das covas e do volume de água aplicado (V) 
$\mathrm{O}$ revestimento lateral das covas, exceto no $\mathrm{R}_{1}$ relativo ao comprimento e $\mathrm{R}_{2}$ referente ao diâmetro (Tabela 1), não contribuiu significativamente para o aumento dessas variáveis em relação às covas desprotegidas. Os valores foram inferiores aos apresentados por Queirós (1997) obtidos de frutos de maracujazeiro irrigado com água de boa qualidade. Quanto aos volumes de água, não foi registrada superioridade estatística entre plantas irrigadas com 5 e $10 \mathrm{~L}$ diariamente (Tabela 1).

As fontes de variação também não exerceram efeito significativo sobre a espessura da casca dos frutos (Tabela 1) e os resultados de 7,76 a $8,47 \mathrm{~mm}$, foram elevados e superiores aos 5,2 mm de Queirós (1997) para o maracujazeiro irrigado com água não salina.

O número de sementes por fruto (Tabela 2), não diferiu entre os tratamentos irrigados com 5 e $10 \mathrm{~L}$ de água. As diferenças estatísticas foram registradas entre o tratamento $R_{0}$ e os tratamentos $\mathrm{R}_{1}, \mathrm{R}_{3}$ e $\mathrm{R}_{4}$, respectivamente. A variação, de 260 a 375 sementes, está compatível e superior à faixa tida como adequada, por Queirós (1998) que foi de 200 a 294 sementes por fruto. Os dados dos tratamentos irrigados com $5 \mathrm{~L}$ ajustaram-se ao modelo cúbico e, nos irrigados com $10 \mathrm{~L}$, o número de sementes cresceu linearmente com o número de faces revestidas (Figura 2).

Quanto ao peso médio das sementes, os valores oscilaram entre 7,43 e 9,93 g e foram inferiores a $19,4 \mathrm{~g}$ fruto $^{-1}$ obtidos por $^{-}$ Queirós (1997) e 18,0 e 21,0 g fruto ${ }^{-1}$ obtidos por Andrade (1998).

O rendimento em polpa (Tabela 2) não foi influenciado pelas fontes de variação, mas os valores oscilaram de 45,68 a $53,20 \%$, com média de $49,72 \%$, e foram superiores aos $39,14 \%$ apresentados por Queirós (1997) e aos 37,23\%, por Andrade (1998) e, conforme Ruggiero et al. (1996) apresentaram-se compatíveis para o mercado "in natura" e para a industrialização.

Os sólidos solúveis totais - "brix (Tabela 2), variaram de 14,01 a $15,90 \%$. O menor valor referiu-se às covas com uma face revestida $\left(R_{1}\right)$ apresentando diferença significativa em relação aos tratamentos das covas com três faces protegidas $\left(\mathrm{R}_{3}\right)$ e não se diferenciando das demais. Não houve registro de significância

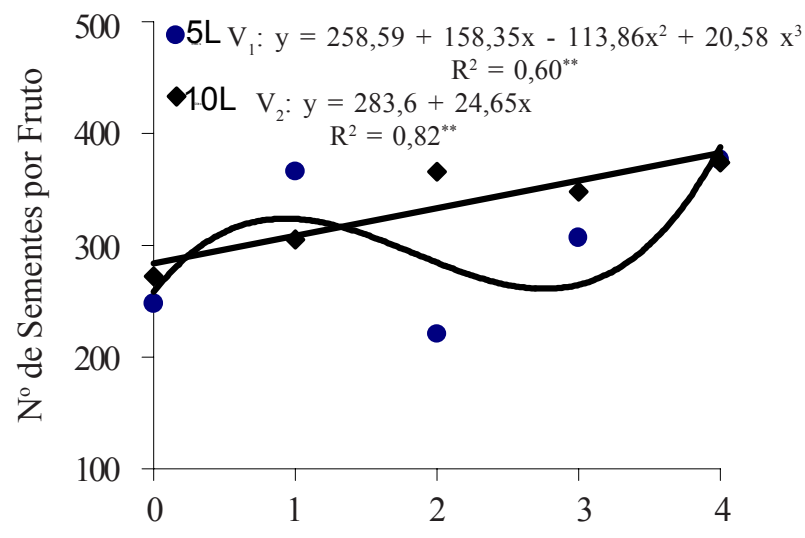

Revestimento Lateral de Covas

Figura 2. Número de sementes por fruto em função do revestimento lateral das covas e do volume de água aplicado (V)

entre os teores nos frutos de plantas irrigadas com 5 e $10 \mathrm{~L}$ de água. De forma geral, os valores expressam qualidade adequada da produção para o consumo ao natural e para industrialização, quando comparados aos $12,70 \%$ de Tocchini et al. (1994), 14,2\% de Queirós et al. (1998) e 15\% de Carvalho et al. (1999) em plantas irrigadas com água não salina. Neste sentido, verifica-se que o elevado nível de salinidade da água de irrigação, superior a $3,0 \mathrm{dS} \mathrm{m}^{-1}$, não influenciou negativamente sobre o ${ }^{\circ}$ brix da polpa dos frutos, e comportamento também observado por Lima et al. (1988) ao constatarem que o teor de sólidos solúveis totais ${ }^{\circ}$ brix do tomateiro (Lycopersicum esculentum Mill.) produzido em solos com diferentes conteúdos de sais, não foi estatisticamente afetado pela salinidade e, também, por Andrade (1998) em maracujazeiro amarelo (Passiflora edulis f. flavicarpa Deg.) irrigado com água salina de condutividade elétrica $2,5 \mathrm{dS} \mathrm{m}^{-1}$.

A acidez total titulável-ATT (Tabela 2), com valores entre 3,33 e 3,87\%, manteve-se na faixa de 2,9 a 3,9\% (Tocchini et al.,1994) e 2,8 a 3,8\% (Queirós,1997) em plantios irrigados com água de boa qualidade.

Tabela 2. Efeito das fontes de variação sobre o número e peso de sementes por fruto, rendimento em polpa, sólidos solúveis totais (SST), acidez titulável total (ATT), relação SST/ATT e vitamina C total de frutos de maracujazeiro amarelo (Passiflora edulis f. flavicarpa Deg.) ${ }^{*}$

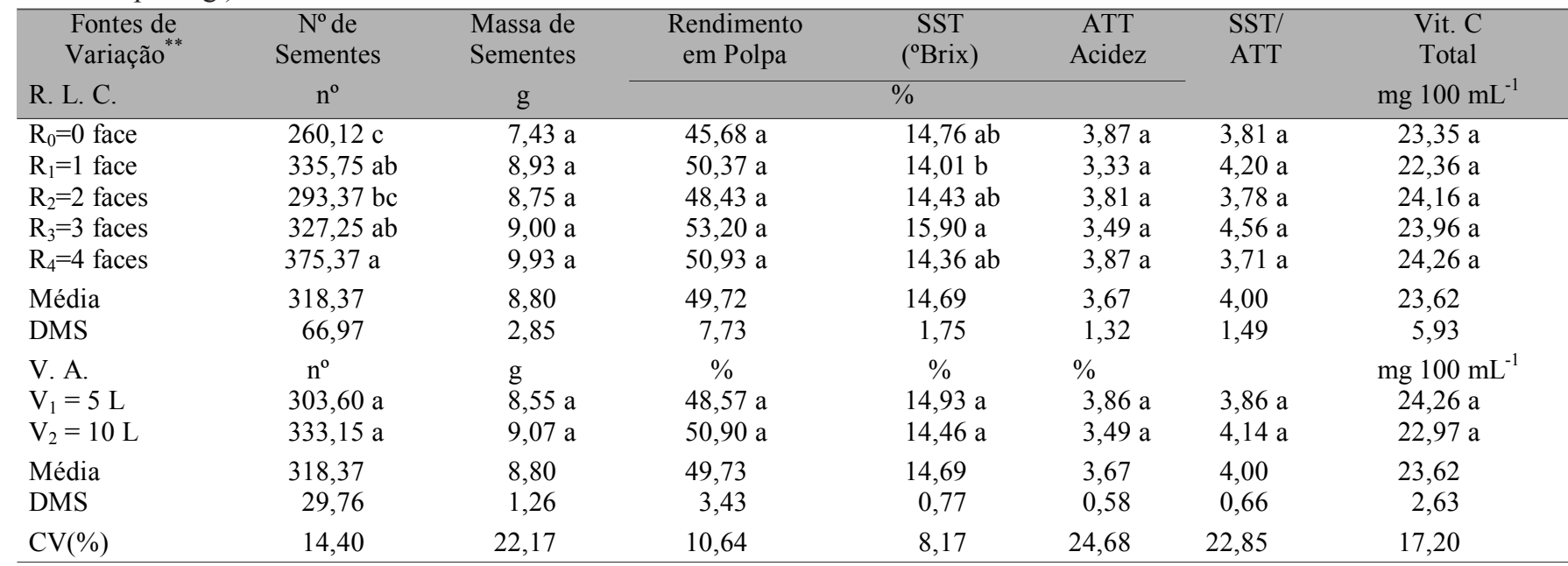


A relação entre os sólidos solúveis totais e a acidez total titulável - SST/ATT (Tabela 2), que define a natureza doce-ácido e sabor das frutas, foi de $4,0 \mathrm{e}$, portanto, superior aos 3,4 obtidos por Colauto et al. (1986) e inferior aos 4,5 de Queirós et al. (1998). Ao se admitir que frutos de maracujá com relação SST/ATT entre 4,2 e 5,2 possuem ótimo sabor (Haendler,1965) observa-se que a elevada salinidade da água não reduziu sensivelmente o sabor da polpa dos frutos.

Os teores de vitamina $\mathrm{C}$ total (Tabela 2), referentes à soma de ácido ascórbico-AA e ácido desidroascórbico-DHAA, variaram de 22,36 a $24,26 \mathrm{mg} 100 \mathrm{~mL}^{-1}$ e não diferiram estatisticamente entre as covas revestidas e não revestidas nem com os volumes de água de irrigação. $\mathrm{O}$ valor médio de

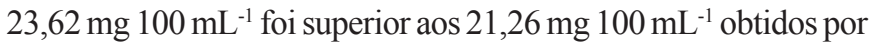
Falconer et al. (1998) e 22,2 mg $100 \mathrm{~mL}^{-1}$ de Carvalho et al. (1999) em frutos provenientes de plantas irrigadas com água não salina; esses resultados mostram que o uso da água salina, de CE $>3,0 \mathrm{dS} \mathrm{m}^{-1}$, não interferiu na produção de vitamina " $\mathrm{C}$ " total dos frutos. Possivelmente o revestimento lateral das covas tenha contribuído para manutenção do solo mais úmido, resultando em menor efeito tóxico e/ou osmótico às plantas de maracujá amarelo. Apesar do elevado nível salino da água sobre a qualidade dos frutos do maracujazeiro, esta situação foi também observada por Andrade (1998) ao verificar que a salinidade da água de irrigação não comprometeu os aspectos internos e externos dos frutos desta frutífera.

\section{CONCLUSÕES}

1. A qualidade da produção, com base no rendimento em polpa, teor de sólidos solúveis totais, acidez total titulável e conteúdo de vitamina $\mathrm{C}$ total, manteve-se nos padrões semelhantes e superiores aos de plantas irrigadas com água de boa qualidade.

2. O comprimento, o diâmetro do fruto e a espessura da casca não variaram estatisticamente nos tratamentos com as covas revestidas com filme polietileno em relação às sem proteção lateral.

3. A interação revestimento das covas versus volume de água, apresentou efeito diferenciado sobre o peso médio dos frutos e o número de sementes por fruto, com superioridade para as plantas irrigadas com $10 \mathrm{~L}$ de água.

4. O elevado nível de salinidade da água não resultou em perdas da qualidade da produção.

\section{LITERATURA CITADA}

Aldrigue, M.L. Desenvolvimento e validação de metodologia analítica, utilizando a CLAE, para determinação de vitamina $\mathrm{C}$ em frutas e seus principais produtos. Campinas: UNICAMP, 1998. 160p. Tese Doutorado

Andrade, R. Resposta do maracujazeiro amarelo ao manejo e salinidade da água de irrigação em um solo não salino .Areia: UFPB,1998. 60p. Dissertação Mestrado
Carvalho, A.J.C. de; Martins, D.P.; Monerat, P.H.; Salassier, B. Produtividade e qualidade do maracujazeiro amarelo em resposta à adubação potássica sob lâminas de irrigação. Revista Brasileira de Fruticultura, Jaboticabal, v.21, n.3, p.333-337, 1999.

Colauto, N.M.; Manica, I.; Riboldi, J.; Mielniczuk, J. Efeito do nitrogênio e potássio sobre a produção, qualidade e estado nutricional do maracujazeiro amarelo. Pesquisa Agropecuária Brasileira, Brasília, v.21, n.7, p.691-695, 1986.

Cunniff, P. (ed.). Official methods of analysis of AOAC International. 16 ed. Gaithersburg: AOAC-International. v.2.1997.412p.

Falconner, P.; Tittoto, K.; Parente, T.V.; Junqueira, N.T.V.; Manica, I. Caracterização físico-química de frutos de seis cultivares de maracujá azedo (Passiflora spp.) produzidos no Distrito Federal. In: Ruggiero, C. (ed.). Maracujá, do plantio à colheita. Jaboticabal: FCAV/UNESP/SBF. 1998. p.365-367.

Haendler, L. La passiflora: as composition chimique et ses possibilites de transformation. Fruits, Paris, v.20, n.5, p.235-245.1965.

Instituto Adolf Lutz. Métodos físicos e químicos para análise de alimentos. São Paulo, SP: IAL, 1985. 533p.

Lima, E.D.P. de A.; Lima, C.A. de A.; Cavalcante, L.F.; Gomes, S.M.S. Avaliação físico-química de polpas de variedades de tomates (Lycopersicum esculentum Mill) comerciais e industriais, produzidas em áreas irrigadas da Paraíba. Revista Tecnologia e Ciência, João Pessoa, v.2, n.4, p.242-247.1988.

Queirós, M.S. de. Tipo de cova e cobertura morta sobre a produção e qualidade dos frutos do maracujazeiro amarelo. Areia: UFPB, 1997. 67p. Dissertação Mestrado

Queirós, M.S.; Lima, E.M. de; Cavalcante, L.F; Oliveira, M.R.T. de. Caracterização físico-química em frutos de maracujazeiro amarelo, no Estado da Paraíba. In: Ruggiero, C. (ed.). Maracujá, do plantio à colheita. Jaboticabal: FCAV/UNESP/SBF. 1998 . 388p.

Ritzinger, R.; Manica, I.; Riboldi, J. Efeito do espaçamento e da época de colheita sobre a qualidade do maracujá amarelo. Pesquisa Agropecuária Brasileira, Brasília, v.24, n.2, p.241-245, Fev.1989.

Ruggiero, C.; São José, A.R.; Volpe, C.A.; Oliveira, J.C.; Duringan, J.F.; Baumgartner, J.G.; Silva, J.R. da; Nakamura, K.; Ferreira, M.E.; Kavati, R.; Pereira, V. de P. Maracujá para exportação: aspectos técnicos da produção. Brasília, DF: EMBRAPA. SPI, 1996.64p. Publicações Técnicas Frupex,19.

São José, A.R.; Rebouças, T.N.H.; Bonfim, M.P.; Pires, M. de M. Situação regional da cultura do maracujá-Nordeste. In: Reunião Técnica de Pesquisa em Maracujazeiro. Londrina, PR: IAPAR/ SBF. 1999.p.4-10.

Teixeira, D.M.M.; Olitta, A.F.L.; Vasconcelos, L.A.B.C. de. Efeito de vários níveis de fertirrigação na cultura do maracujazeiro amarelo (Passiflora edulis var. flavicarpa). Engenharia Rural, Piracicaba, v.1, n.1, p.1-76. 1990.

Tocchini, R.P.; Nisida, L.A.C.; Hashizume, T.; Medina, J.C.; Turatti, J.M. Processamento: produtos, caracterização e utilização. In: ITAL. Maracujá. 2 ed. Campinas: ITAL,1994. p.161-192. 